\title{
Linear tuning of microwaves power for the extraction of bioactive molecules from citrus peels
}

\author{
GIUSEPPE D'AURIA $^{1 *}$, GIACINTO D'AMORE ${ }^{2}$, ALDO ROMANO $^{1}$ and \\ FRANCESCO MARRA ${ }^{2}$
}

\author{
${ }^{1}$ Dipartimento di Farmacia, Università degli Studi di Salerno, Via Giovanni Paolo II, 132, 84085 \\ Fisciano, Salerno, Italy \\ ${ }^{2}$ Dipartimento di Ingegneria Industriale, Università degli Studi di Salerno, Via Giovanni Paolo II, 132, \\ 84085 Fisciano, Salerno, Italy
}

\section{CONFERENCE FULL PAPER}

Received: August 11, 2020 • Accepted: October 06, 2020

Published online: November 26, 2020

(C) 2020 The Author(s)

\begin{abstract}
In the last years, an alternative and convenient way to composting and/or bio-gasifying food waste is represented by the extraction of high value bioactive components from such materials. In particular, essential oils contained in matrices such as orange or lemon peels may represent high value bioactive components for the nutraceutical and pharma industry. In recent years, microwave assisted processes have been considered for use in solvent-free extraction. However, the microwave assisted extraction is often performed in very simple microwave systems, without an accurate control, if any, of the power release.

In this work, the linear tuning of microwave power for the extraction of bioactive components from citrus peels is discussed, with emphasis on the consequent process yield and extract characteristics. Chemical analysis of the extracted mixture showed the presence of quite a number of active molecules of relevant interest for pharmaceutical and nutraceutical industries, such as glycoside flavanone (Hesperidin and Eriocitrin) in lemon peels, and polymethoxylated flavones (Nobiletin and Sinensetin) in orange peels.
\end{abstract}

\section{KEYWORDS}

microwaves, food processing, bioactive compounds

\footnotetext{
"Corresponding author. E-mail: gdauria@unisa.it
} 


\section{INTRODUCTION}

The term citrus refers to the cultivated plants belonging to the genus Citrus of the subfamily Aurantioideae (Rutaceae family) and to their fruits (oranges, lemons, mandarins, clementines, bergamot, chinotto). Even if originating in in India and Far East, all citrus fruits today spontaneously grow in Indonesia, Malaysia, New Guinea, and Philippines. The species reached Europe at different times. Cedar, supposed to be the first to come, was known among the ancient Romans as the Persian apple. Citrus fruits are widely cultivated in the subtropical belt of the whole world.

Italy occupies a prominent place in the world production, with a share of around $5 \%$ of the world production, with an annual production of 4 million tons, that is a remarkable amount if referred to the Country size. The production is concentrated in the southern regions, with Sicily in the front row (about two thirds of national production), followed by Calabria, Campania, Puglia, Basilicata, and Sardinia.

The citrus processing industries generate huge amounts of waste every year: it has to be noted that only $40 \%$ of the total fruit mass is transformed in food products, while the remaining $60 \%$ becomes waste. This latter is rich in bioactive molecules such as flavonoids, carotenoids, essential oils, polyphenols, vitamins, and pectine (Petra et al., 2011) that are of a basic importance for nutraceutical and cosmetic industries. However, traditional extraction techniques present a number of significant disadvantages as they require very long processing times, typically involve use of toxic organic solvents with the relevant drawbacks of exposure of the operators, disposal and, above all, unsatisfying quality of the final extract (Ferhat et al., 2007).

Therefore, the agri-food sector has been investing, in the last years, time and money to develop new extractive procedures that could reduce use of organic solvents, energy consumption, process times, and $\mathrm{CO}_{2}$ emissions, thus respecting the basic principles of green chemistry, with consequent money saving and reduced environmental impact (Chemat et al., 2012). Such an approach could transform waste into a real resource. The wastes can thus be seen as by-products or, even better, co-products. Recently, microwave assisted extraction (MAE) has been considered as one of the most sustainable innovative extraction techniques. With the dual mechanism of ionic conduction and dipole rotation, microwave energy can rapidly heat solvents to extract analytes from the sample matrix into the solvents (Leonelli and Villa, 2008). MAE has been successfully applied in extracting various substances from plant matrices, including flavonoids from grape pomace, anthocyanins from blackcurrant (Nora et al., 2013), caffeine from green coffee beans (Upadhyay et al., 2012), pesticides and metals.

In this work the solvent free microwave extraction technique (Lucchesi et al., 2004), as an alternative to the traditional ones, has been analyzed, based on microwave heating, to obtain essential oils, hydrolates and mixtures of polyphenols from orange and lemon peels, deriving from the manufacturing process. The technique has been applied to citrus pulp, residue from processing of lemons (variety Sfusato Amalfitano ${ }^{\mathrm{TM}}$ ) and/or oranges (variety Tarocco $^{\mathrm{TM}}$ ), planted in Amalfi Coast. Actually, heating of the internal, native water contained in the vegetable matrix by microwaves and causes bursting of glands and oleiferous receptacles (Li et al., 2013). The process frees essential oil, which is thus extracted by the water by azeotropic distillation. The extracted vapors then pass through a condenser outside the microwave cavity.

The operating variables were studied which mostly influence the extraction process.

Aim of the work was to investigate the effect on the extraction process of the operating variables either related to the raw materials (humidity and size of matrices) or of the plant 
arrangement (mode of microwaves power supply, duration of the process). Results are examined in terms of percentage yield of citrus peel oil, hydrolates and mix of flavonoids).

\section{MATERIALS AND METHODS}

\section{The extraction plant}

The work was carried in an extraction apparatus consisting of a microwave cavity, Whirlpool MWF 426 SL, $800 \mathrm{~W}$ (cavity size: $L=31.7 \mathrm{~cm} ; H=21 \mathrm{~cm} ; W=31.5 \mathrm{~cm}$ ), 2,450 MHz, equipped with a properly designed extraction chamber and a condenser. A $2.5 \mathrm{~cm}$ hole, made in the center of the cavity top side, allowed the vapors coming from the extraction chamber to be conveyed through a food-grade silicone tube to the liebig condenser (Fig. 1). A rotating paddle guarantees the microwave field homogenization, also avoiding the need for a rotating plate. The sample temperature is monitored through the use of optical fibers Fisio Tecnologies ${ }^{\circledR}$ ( -40 to $300{ }^{\circ} \mathrm{C}$ ).

The apparatus has been operated in two modes of microwaves power supply: (i) in the cavity named " $\mathrm{A}$ " power supply is regulated by a duty-cycle, with magnetron either at maximum power $(800 \mathrm{~W})$ or turned off, alternating the time fraction of functioning according to the nominal mean power required (square wave) (see Fig. 2a); (ii) in the "B" cavity, a $5 \mathrm{kV}$ specially designed power supplier, 1,000 W maximum power, equipped with a control feedback, allows a linear regulation of the microwaves power, that is supplied with continuity, by modulating the current intensity (Fig. 2b).

\section{The vegetables matrices: Lemon and orange peels}

In each experiment, $150 \mathrm{~g}$ of peels were subjected to microwaves. Before each test, the humidity of the initial sample was measured, by a MB45 Ohaus, resulting for all tests is in the range $68-80 \%$.

\section{The extraction runs}

Experimental tests were carried out aiming at process intensification. Runs were performed in the power range $150-600 \mathrm{~W}$, that gave the best results. Actually, operating above $600 \mathrm{~W}$ involves the risk of burning the vegetable matrices before distillation occurs, whereas to operate at a power below $150 \mathrm{~W}$ requires a too long extraction time.

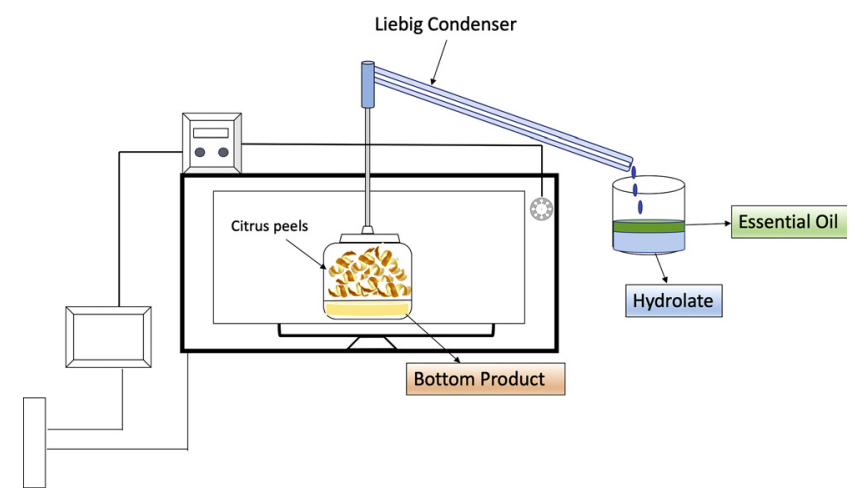

Fig. 1. Extraction Apparatus. Three products of the extraction are highlighted 


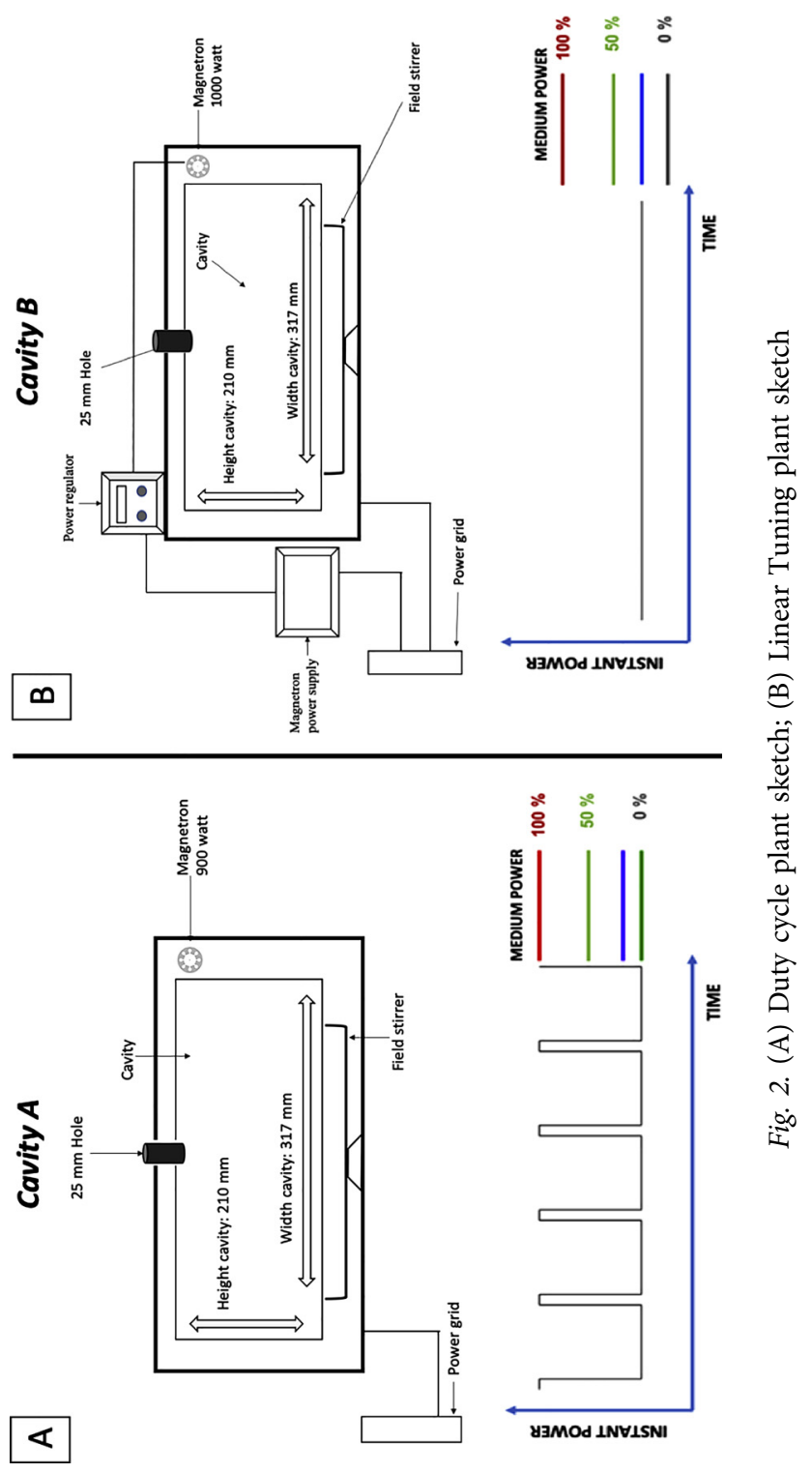


Table 1. Operating conditions

\begin{tabular}{lcccc}
\hline Level & Power $(\mathrm{W})$ & Time $(\mathrm{min})$ & Specific power $(\mathrm{W} / \mathrm{g})$ & Total energy supplied (kJ) \\
\hline 1 & 150 & 40 & 1 & 360 \\
2 & 350 & 20 & 2.3 & 420 \\
3 & 550 & 15 & 3.6 & 495 \\
\hline
\end{tabular}

Experiments have been done at three power levels, namely 150, 350, and $550 \mathrm{~W}$ (Table 1). Times of the runs were decreased as power increased, to avoid the risk of matrix sample overheating and, consequently, bioactive molecules spoiling.

Bottom products are collected in the extraction chamber at the end of the process. Essential oils and aromatic water leaving the chamber as head products are collected and condensed at the cavity exit (Fig. 2). Fractional yield for each product is calculated in term of (mass of product)/ (initial mass of vegetable matrix).

\section{The extraction products analysis}

UPLC PDA analyses were performed on Ultra Pressure Liquid Chromatographic Acquity system (UPLC, Acquity I-Class, Milan, Italy) consisting of a Waters Acquity binary solvent manager, a sample manager (FL), a Column Manager (CM-A), PDA eLambda detector (equipped with a $500 \mathrm{~nL}$ detector flow cell volume), Acquity QDa detector and a degassing system. The whole configuration was driven by Empower software v3.0 from Waters Corporation. UPLC analysis was carried out on Kinetex C18 $150 \times 2.1 \mathrm{~mm}(100 \AA$ ) $)$, packed with 2.6 $\mu \mathrm{m}$ core shell particles, column (Phenomenex, Bologna, Italy). The optimal mobile phase consisted of $\mathrm{H}_{2} \mathrm{O}(\mathrm{A})$ and $\mathrm{ACN}$ (B) both acidified by formic acid $0.1 \% v / v$. Analysis was performed in gradient elution as follows: $0-3.00 \mathrm{~min}$, isocratic to $2 \% \mathrm{~B} ; 3-25.00 \mathrm{~min}, 2-50 \% \mathrm{~B}$; 25-30.00 $\mathrm{min}, 50-80 \% \mathrm{~B}$; $30-30.01 \mathrm{~min}$, isocratic to $82 \% \mathrm{~B}$; then $5 \mathrm{~min}$ for column re-equilibration. Flow rate was $0.4 \mathrm{~mL} / \mathrm{min}$. Column oven temperature was set to $40{ }^{\circ} \mathrm{C}$. Injection volume was $2 \mu \mathrm{L}$ of extract. The following PDA parameters were applied: sampling rate, 20 points/sec; resolution, $1.2 \mathrm{~nm}$. Data acquisition was set in the range $190-800 \mathrm{~nm}$ and chromatograms were monitored at $280 \mathrm{~nm}$ and $330 \mathrm{~nm}$ at the maximum absorbance of the compounds of interest. MS detection of polyphenol extracted was operated in both positive and negative ionization mode.

\section{RESULTS AND DISCUSSION}

\section{Effect of power supply}

For all products, yield in operations performed in Cavity B (linear microwaves tuning), is larger with respect to Cavity A (Table 2). It is hypothesized that duty cycle in Cavity A hinders the distillation process since water, when magnetron is turned off, keeps on evaporating taking the necessary energy from the vegetable matrix that, in turn, cools down, thus stopping the process. On the contrary, this latter is favored in Cavity B, that keeps the plant temperature constant with time by supplying a controlled power. As a consequence, yield in essential oil is almost negligible when operating with the duty-cycle of Cavity A. Hydrolate and Bottom products yields are affected too by the mode of power supply, being remarkably lower with Cavity A. 
Table 2. Difference yields between Cavity A and Cavity B

\begin{tabular}{|c|c|c|c|c|c|c|}
\hline \multirow[b]{3}{*}{ Level } & \multicolumn{3}{|c|}{ Cavity A } & \multicolumn{3}{|c|}{ Cavity B } \\
\hline & \multicolumn{3}{|c|}{ Yields\% } & \multicolumn{3}{|c|}{ Yields\% } \\
\hline & O.E & Bottom product & Hydrolate & O.E & Bottom product & Hydrolate \\
\hline 1 & $0 \%$ & $21.8 \%$ & $12.21 \%$ & $0.45 \%$ & $29.6 \%$ & $19.7 \%$ \\
\hline 2 & $0 \%$ & $27.74 \%$ & $14.8 \%$ & $0.37 \%$ & $33.82 \%$ & $22.57 \%$ \\
\hline 3 & $0 \%$ & $25.35 \%$ & $28.23 \%$ & $0.24 \%$ & $31.5 \%$ & $36.01 \%$ \\
\hline
\end{tabular}

\section{Effect of power}

Three levels of specific power have been used in performing the experimental runs (see Table 1). Results show that the lower power level (1 W/g) favors the essential oil extraction (Graph 1), whereas amount of bottom products and hydrolate increases when applying higher powers levels $(2.3 \mathrm{~W} / \mathrm{g}$ and $3.6 \mathrm{~W} / \mathrm{g})$. In particular power level $2(2.3 \mathrm{~W} / \mathrm{g})$ favors the bottom product extraction, while power level 3 (3.6 W/g) favors hydrolate extraction (Graph 2).

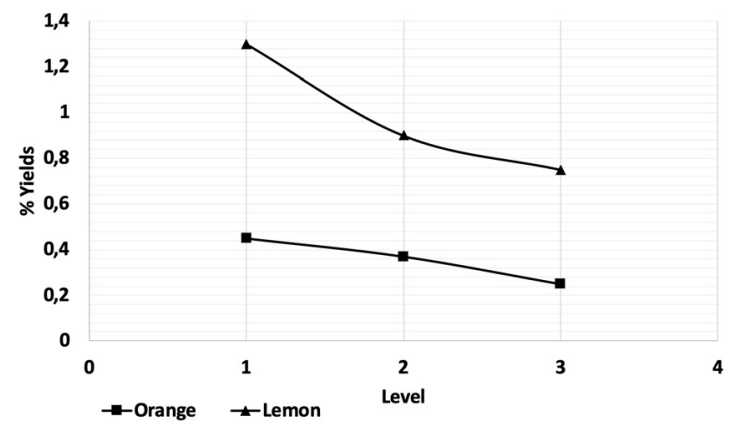

Graph 1. Yields orange and lemon essential oil

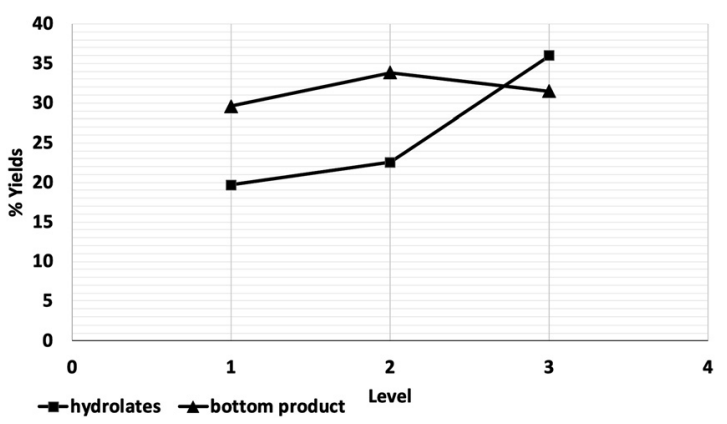

Graph 2. Yields orange and lemon hydrolate and bottom product 


\section{Effect of humidity}

The best results were obtained using vegetable matrices with humidity in the range $70-80 \%$. When the value is below $50 \%$, the ability of sample to generate heat by water interaction with microwaves decreases. As a consequence, the amount of essential oils decreases. Conversely, if humidity exceeds $80 \%$, it causes overheating of the plant matrix with possible degradation of the more volatile compounds.

\section{Analysis of bottom products}

The presence of various molecules such as polyphenols, polymethoxiflavones and vitamins has been highlighted in the bottom products extracted from lemon peels. In detail, 27 polyphenols were identified, as reported in Table 3.

In particular, glycosidic flavanones such as eriocitrin (peak 18) and hesperidin (peak 25) (Fig. 3), molecules with overt antioxidant, antiphlogistic (Parhiz et al., 2015), hypotensive and hypocholesterolemic properties have been isolated (Hiramitsu et al., 2015).

Table 3. List of 27 substances identified in the bottom product extracted from lemon peel

\begin{tabular}{|c|c|}
\hline Peak & Compound \\
\hline 1 & Quinic acid \\
\hline 2 & Coumaroylquinic acid \\
\hline 3 & Coumaroylquinic acid isomer \\
\hline 4 & Coumaroyl-glucaratc or -galactatc \\
\hline 5 & Coumaroyl-glucarate or -galactate isomer I \\
\hline 6 & Dihydro-caffeoyl-o-glucoside \\
\hline 7 & Coumaroyl-glucarate or -galactate isomer II \\
\hline 8 & Coumaroyl-glucaratc or -galactatc isomer III \\
\hline 9 & Feruloyl-lucarate or -galactate \\
\hline 10 & Unknown + hydroxy-methil-glutaryl \\
\hline 11 & Unknown + hydroxy-methil-glutaryl \\
\hline 12 & Dihydro-feruoyl-O-glicoside \\
\hline 13 & Dihydro-fcruoyl-O-glicosidc isomer \\
\hline 14 & $\begin{array}{l}\text { Viccnin II (Apigcnin-6,8-di-C-D- } \\
\text { glucopyranoside) }\end{array}$ \\
\hline 15 & Chrysoeriol-6,8-di-C- $\beta$-D-glucoside \\
\hline 16 & $\begin{array}{l}\text { Diosmetin-6,8-di-C- } \beta \text {-D-glucopyranoside } \\
\text { (Lucenin-2-4' -methyl ether) }\end{array}$ \\
\hline 17 & $\begin{array}{l}\text { Dihydro-fcruloyl-glucosil-hydroxy-mcthil- } \\
\text { glutaryl }\end{array}$ \\
\hline 18 & Eriodictyol-7-O-rutinoside (Eriocitrin) \\
\hline 19 & Kacmpfcrol-3-O-rutinoside \\
\hline 20 & $\begin{array}{c}\mathrm{N} \text { åringen in-7-O-rutinoside (Narirutin, } \\
\text { Isonaringin) }\end{array}$ \\
\hline 21 & $\begin{array}{l}\text { Hesperctin-7-O-neohespcridoside } \\
\text { (Neohesperidin) }\end{array}$ \\
\hline 22 & Isorhamnetin-3-O-rutinoside \\
\hline 23 & Limocitrin-O-glucosil-O-rhamnosidc \\
\hline 24 & $\begin{array}{l}\text { Limocitrin-O-glucosil-hydroxy-methil-glutaryl- } \\
\text { O-glucose-ester }\end{array}$ \\
\hline 25 & Hesperctin-7-O-rutinoside (Hesperidin) \\
\hline 26 & $\begin{array}{l}\text { Limocitrol-O-glucosil-hydroxy-methil-glutaryl- } \\
\text { O-glucose-ester }\end{array}$ \\
\hline 27 & $\begin{array}{l}\text { Limocitrin-O-glc-di-hydroxymcthilglutaryl- } \\
\text { caffcoyl }\end{array}$ \\
\hline
\end{tabular}




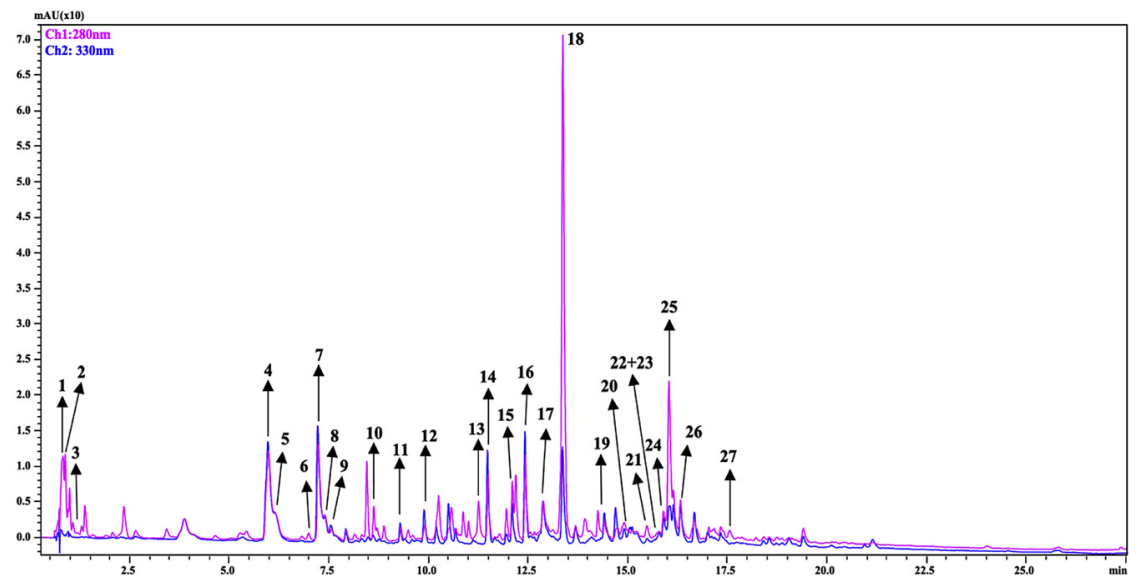

Fig. 3. LC/MS chromatogram of a bottom product extracted from lemon peels

1) Rutin

2) Vicenin-2

3) Lucenin-2,4'- methyl ether

4) Narirutin

5) Hesperidin

.

(a)

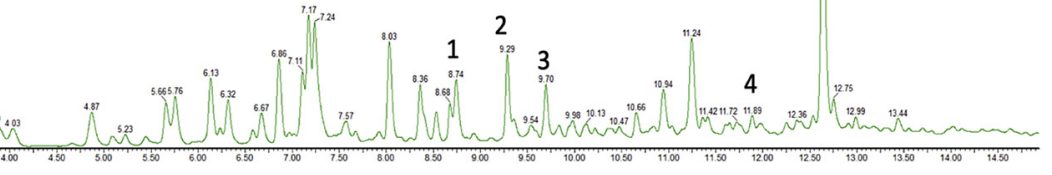

Fig. 4. LC/MS chromatogram of a bottom product extracted from orange peels - Part 1

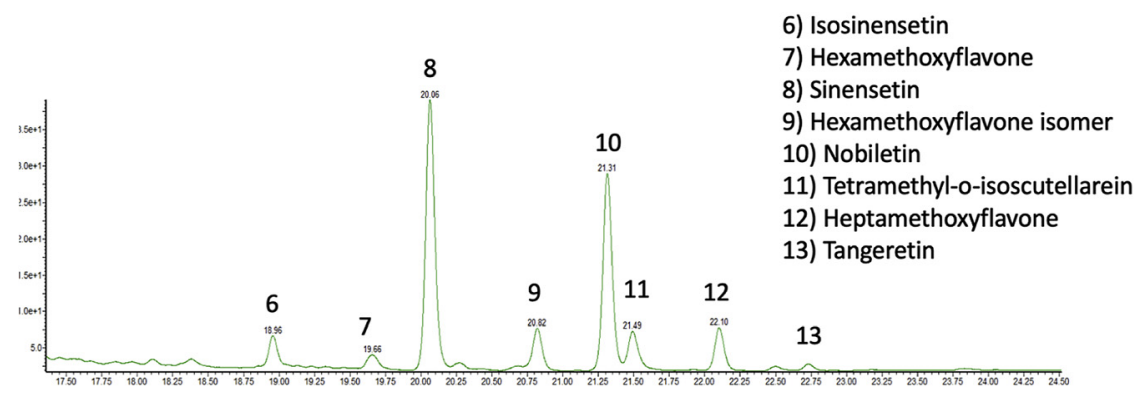

Fig. 5. LC/MS chromatogram of a bottom product extracted from orange peel - Part 2 
The same kind of preliminary analysis was carried out on the bottom products extracted from orange peels. In this case, the most abundant compound was Hesperidin (peak 5) (Fig. 4).

Particularly interesting is the presence of polymethoxiflavones, nobiletin (peak 10) and sinensetin (peak 8) (Fig. 5). In fact, antitumor activity of those compounds is well recognized (Wang et al., 2014).

\section{CONCLUSIONS}

Results of the experimental tests show that the microwave power must be supplied via a linearly variable delivery mode, as it guarantees feasibility and yields of the extraction of valuable compounds from waste derived by the citrus industries. Glycoside flavanone such as Hesperidin and Eriocitrin are actually found in the extract from lemon peels, whereas polymethoxylated flavones such as Nobiletin and Sinensetin are mostly found in oranges.

Low power operations appear to best work in the extraction of essential oils and hydrolates, while high powers are best suitable for the extraction of flavonoids.

It has been also seen that use of commercial apparatuses working with a power modulation by duty-cycle, i.e., alternating magnetron start and shutdown phases to produce a sort of pulsewidth modulation, hinders the reproducibility of the extraction protocols.

\section{ACKNOWLEDGMENTS}

This work was done in the framework of Microexativa project, run at University of Salerno, Italy.

“Progetto cofinanziato dall'Unione Europea, dallo Stato Italiano e dalla Regione Campania, nell'ambito del POR Campania FESR 2014-2020" Microexativa - Estrazione senza solvente, mediante microonde, di principi attivi per la cosmetica e la nutraceutica da matrici di Cannabis sativa"

\section{REFERENCES}

Chemat, F., Vian, M., and Cravotto, G. (2012). Green extraction of natural products: concept and principles. IJMS, 13: 8615-8627. https://doi.org/10.3390/ijms13078615.

Ferhat, M.A., Meklati, B.Y., and Chemat, F. (2007). Comparison of different isolation methods of essential oil fromCitrus fruits: cold pressing, hydrodistillation and microwave 'dry' distillation. Flavour and Fragrance Journal, 22: 494-504. https://doi.org/10.1002/ffj.1829.

Hiramitsu, M., Shimada, Y., Kuroyanagi, J., Inoue, T., Katagiri, T., Zang, L., Nishimura, Y., Nishimura, N., and Tanaka, T. (2015). Eriocitrin ameliorates diet-induced hepatic steatosis with activation of mitochondrial biogenesis. Scientific Reports, 4: 3708. https://doi.org/10.1038/srep03708.

Leonelli, C. and Villa, C. (2008). Applicazioni delle microonde in chimica analitica. In: Leoni, C. (Ed.), Il Riscaldamento a Microonde. Principi ed Applicazioni. Pitagora, Bologna, p. 205.

Li, Y., Fabiano-Tixier, A.S., Vian, M.A., and Chemat, F. (2013). Solvent-free microwave extraction of bioactive compounds provides a tool for green analytical chemistry. Trends in Analytical Chemistry, 47: $1-11$. 
Lucchesi, M.E., Chemat, F., and Smadja, J. (2004). Solvent-free microwave extraction of essential oil from aromatic herbs: comparison with conventional hydro-distillation. Journal of Chromatography A, 1043: 323-327. https://doi.org/10.1016/j.chroma.2004.05.083.

Nora, P., Sándor, B., Eva, P., Liisa, M., Miklós, G., Ernő, G., Cecilia, H., and Riitta, L.K. (2013). Microwaveassisted extraction of anthocyanins from black currant marc. Food and Bioprocess Technology, 6(10): 2666-2674.

Parhiz, H., Roohbakhsh, A., Soltani, F., Rezaee, R., Iranshahi, M. (2015). Antioxidant and anti-inflammatory properties of the citrus flavonoids hesperidin and hesperetin: an updated review of their molecular mechanisms and experimental models. Phytotherapy Research, 29: 323-331. https://doi.org/10. 1002/ptr.5256.

Petra, C., Katalin, B.-B., Zsófia, C., Sándor, B., and Cecilia, H. (2011). Simultaneous recovery of pectin and colorants from solid agro-wastes formed in processing of colorful berries. Progress In Agricultural Engineering Sciences, 7(1): 65-80.

Upadhyay, R., Ramalakshmi, K., Jagan Mohan Rao, L. (2012). Microwave-assisted extraction of chlorogenic acids from green coffee beans. Food Chemistry, 130(1): 184-188.

Wang, L., Wang, J., Fang, L., Zheng, Z., Zhi, D., Wang, S., Li, S., Ho, C.-T., and Zhao, H. (2014). Anticancer activities of citrus peel polymethoxyflavones related to angiogenesis and others. BioMed Research International, 2014: 1-10. https://doi.org/10.1155/2014/453972.

Open Access. This is an open-access article distributed under the terms of the Creative Commons Attribution-NonCommercial 4.0 International License (https://creativecommons.org/licenses/by-nc/4.0/), which permits unrestricted use, distribution, and reproduction in any medium for non-commercial purposes, provided the original author and source are credited, a link to the CC License is provided, and changes - if any - are indicated. 